\title{
Tricholithobezoar Causing Gastric Perforation
}

\author{
Juliana Santos Valenciano ${ }^{a}$ Ronaldo Nonose ${ }^{a}$ \\ Rodrigo Bragattini Cruz ${ }^{\mathrm{a}}$ Daniela Tiemi Sato ${ }^{\mathrm{b}}$ \\ Felipe Cappellette Monteiro Fernandes ${ }^{b}$ \\ Enzo Fabrício Nascimento ${ }^{a} \quad$ Carlos Augusto Real Martinez $^{c}$ \\ ${ }^{a}$ Department of General Surgery, São Francisco University Hospital, \\ ${ }^{b}$ São Francisco University Medical School and ${ }^{\mathrm{C}}$ Post-graduate Program in Health \\ Sciences of São Francisco University, Bragança Paulista (SP), Brazil
}

\section{Key Words}

Bezoar · Trichobezoar - Hair balls · Trichotillomania - Lithiasis · Emotional disturbance . Therapy

\begin{abstract}
A bezoar is an intraluminal mass formed by the accumulation of undigested material in the gastrointestinal tract. Trichobezoar is a rare condition seen almost exclusively in young women with trichotillomania and trichotillophagia. When not recognized, the trichobezoar continues to grow, which increases the risk of severe complications such as gastric ulceration and even perforation. Formation of a gallstone within the trichobezoar (tricholithobezoar) is an event that has not yet been described. We report the case of a 22-year-old woman admitted to the emergency room with signals and symptoms of an epigastric mass and perforative acute abdomen. Radiological study revealed bilateral pneumoperitoneum. Personal history revealed depressive syndrome, trichotillomania and trichophagia. With a diagnosis of visceral perforation, an urgent exploratory laparotomy was performed. This confirmed the diagnosis of gastric perforation due to a large trichobezoar with the formation of a gastrolith that was removed by anterior gastrotomy. Biochemical study of the gastric stone revealed that it was composed of bile salts. There were no complications. The patient was discharged on the 5 th postoperative day and was referred for psychiatric treatment.
\end{abstract}

\section{Introduction}

A gastric bezoar (GB) is an intraluminal mass formed by the accumulation of undigested material [1]. GB is rare, with an estimated incidence of less than $1 \%$ in the general population [2,3]. Gastric trichobezoar (GT) is the most frequent type of bezoar found in the stomach [4]. Generally, it is described as a secondary symptom in young 
girls with long hair, mainly arising from trichotillomania (pulling out of their own hair) and trichophagia (eating of hair) [5, 6]. Potential complications of GT include intestinal obstruction and gastric perforation resulting in peritonitis and pancreatitis [7, 8].

Formation of an enterolith in the gastrointestinal system generally occurs in a jejunoileal or Meckel diverticulum $[9,10]$. To the best of our knowledge, the primary formation of a bile salt calculus (gastrolith) in the stomach of a patient with GT without signs of cholelithiasis has not yet been described. Here, we report the case of a young woman with a long history of trichotillomania and trichophagia who developed gastric perforation due to the presence of a tricholithobezoar.

\section{Case Report}

A 22-year-old woman presented with a 4-day history of generalized abdominal pain, mainly located in the epigastric region, and continuous upper abdominal distension. After 2 days, she presented with significant worsening of her pain associated with nausea and vomiting. She had noted a weight loss of $5 \mathrm{~kg}$ in the previous 4 months. The woman's parents reported a past medical history of compulsive trichotillomania and trichophagia that had started 10 years earlier. At physical examination, she was dehydrated with fever $\left(38^{\circ} \mathrm{C}\right)$ and had a blood pressure of $100 / 60 \mathrm{~mm} \mathrm{Hg}$. Physical examination of the abdomen revealed generalized abdominal tenderness, abdominal distension, signs of peritonitis, and pneumoperitoneum. A large, non-tender mass was palpated in the epigastrium (Lamerton's sign). On physical examination of the scalp, the patient presented with traumatic alopecia over the parietal, temporal and occipital regions (ㅎig. 1).

Laboratory investigations revealed hemoglobin $10.7 \mathrm{~g} / \mathrm{dl}$, elevated white cell count $(14,700$ leukocytes), $\mathrm{Na}^{+} 140.0 \mathrm{mmol} / \mathrm{l}, \mathrm{K}^{+} 3.8 \mathrm{mmol} / \mathrm{l}$, creatinine $1.0 \mathrm{mg} / \mathrm{dl}$, and serum amylase $30 \mathrm{IU} / \mathrm{l}$. Radiography of the chest and abdomen showed diffuse dilation of the stomach and proximal small bowel with multiple air-fluid levels and the presence of bilateral pneumoperitoneum. Subsequent ultrasonography of the abdomen and pelvis revealed the presence of an irregular hyperechoic mass inside the stomach and a moderate amount of free fluid diffusely spread in the peritoneal cavity and pneumoperitoneum. With a diagnosis of perforated acute abdomen, an emergency laparotomy was performed. The abdominal cavity was opened by an upper midline incision. 2,500 ml of purulent fluid was found in the cavity and the presence of a perforated gastric ulcer ( $2 \mathrm{~cm}$ in diameter) located in the anterior wall of the stomach was noted. After the abdominal cavity was cleaned, a $7 \mathrm{~cm}$ gastrotomy was performed in the anterior portion of the gastric wall. The interior of the stomach was completely filled with large balls of hair (fig. 2). A large, black trichobezoar $(27 \times 9 \times 8 \mathrm{~cm})$ weighing $790 \mathrm{~g}$ was removed through the gastrotomy. The antral extremity of the trichobezoar displayed a large expanse of yellowish calculus, with the consistency of a stone, measuring $8 \mathrm{~cm}$ in its largest diameter (fig. 3 ). After complete removal of the ulcerated lesion with wide surgical margins for histopathological study, the gastric wall was reconstituted by single-layer monofilament absorbable stitches. Histopathological analysis showed that the bezoar comprised mainly human hair but also food waste and vegetal fibers. Biochemical analysis of the gastrolith showed that it was composed of choleic acid and calcium oxalate. The patient presented a favorable postoperative course and was discharged on the 5th day. Currently, 6 months after surgery, she does not complain of any abdominal discomfort, has recovered the initial weight loss, and is undergoing psychiatric treatment.

\section{Discussion}

The term 'bezoar' comes from the Arabic word 'bedzehr' or the Persian word 'padzhar' [11]. GB was described for the first time during the autopsy of a patient who died from gastric perforation and peritonitis [12]. GBs are classified by their composition as phytobezoars (composed of vegetables fibers), trichobezoars (balls of hair or hair-like fibers), diospyrobezoars (persimmon), pharmacobezoar (pills), 
lactobezoars (composed of milk curd), lithobezoars (fragments of stones) or plasticobezoars (plastic) [13,14]. GB mainly formed by hair represents $50 \%$ of all bezoars, and it is estimated that the incidence in the general population varies from $0.4 \%$ to $1 \%$. However, as the condition occurs mainly in patients with psychiatric disorders, it is possible that this incidence is underestimated [15].

GT is commonly identified in young women generally between the ages of 13 and 20 years [15]. In a classic review, only 31 out of 232 cases (13\%) occurred in patients below the age of 9 years [6]. The diagnosis should always be suspected in patients who have a long history of trichotillomania with trichophagia as detected in the patient described here [6, 8]. In most cases, the trichobezoar is confined to the stomach, but it can migrate through the pylorus into the jejunum, ileum or even the colon. This condition is known as Rapunzel syndrome in allusion to the Grimm brothers' fairy tale [16].

The formation of GT is still not fully understood. GT likely form when hair strands, escaping peristaltic propulsion because of their slippery surface, are retained in the folds of the gastric mucosa [11]. The hairball goes unnoticed and the trichobezoar continues to grow in size and weight due to the continuous deglutition of hair. At its largest, the GT assumes the shape of the stomach, usually as a single solid mass [11]. In the patient described here, the GT completely occupied the stomach and took on its shape. The hair fibers were blackened, due to denaturation of the hair protein by gastric acidic contents, and covered with mucus-containing food waste. The decomposition and fermentation of fats and the decomposition of retained food gave off a putrid smell.

The symptoms presented depend of the size of the trichobezoar and the presence of complications. A large trichobezoar is generally retained in the stomach due to the presence of a sphincter at the pylorus, and the related symptoms may be similar to those of pyloric obstruction. Reviews showed that epigastric pain (70.2\%), epigastric mass (70\%), nausea and vomiting (64\%), hematemesis (61\%), weight loss (38\%), and diarrhea and constipation (32\%) are the most common symptoms [6, 11]. Severe halitosis and patchy alopecia, a previous history of trichotillomania, trichophagia, and the presence of alopecia as identified in the patient described here may suggest a preoperative diagnosis of trichobezoar [11]. Most patients present malabsorptionrelated complications that include protein-losing enteropathy, iron deficiency anemia, and megaloblastic anemia [11]. If the GT is slow-growing and left untreated for a long time, it increases in size, with the risk of severe complications such as gastric obstruction, ulceration, and even perforation of the stomach, as occurred in the patient described here. The largest trichobezoars can reduce blood supply to the mucosa of the stomach, causing ischemia, ulceration and eventually perforation, typically found along the lesser gastric curvature, where the blood supply is limited [17]. Recently, a review of 108 cases of GT showed that the most common complication is perforation of either the stomach or the intestine (occurring in $10.1 \%$ of cases), followed by intussusceptions (1.85\%), pancreatitis (0.92\%) and cholangitis $(0.92 \%)$ [18].

The formation of bile salt calculi inside the stomach in association with a large GT has not yet been described. Generally, the presence of bile salt calculi inside the stomach occurs due to the migration of stones formed in the gallbladder, which reach the stomach through a biliary fistula. A review of the literature revealed only 1 case 
presenting with intragastric calculi and GB [19]. Although the pathogenesis of intragastric bile sat calculi is unknown, it is possible that the gastric stasis caused by trichobezoar leads to modifications in gastric $\mathrm{pH}$ and changes the bacterial flora, leading to the precipitation of non-conjugated bile acids inside the trichobezoar and ultimately forming the gastrolith. In this patient the presence of a large gastrolith, with a diameter of $8 \mathrm{~cm}$ (which is wider than the pylorus), within the trichobezoar and independent of gallstones or an intestinal-biliary fistula, suggests that the calculus was formed primarily in the stomach, probably due to the reflux and subsequent stasis of duodenal contents that were found in the stomach.

The management of a GB must involve removal of the mass and prevention of recurrence by addressing the underlying physical or emotional cause [11]. The best option for the treatment of GB depends on the presence of complications as well as the GB's consistency, size and localization. Small, simple GTs can be extracted by endoscopy through the use of a basket or direct suction [20]. The endoscopic procedure is less effective for GTs, particularly for those $>20 \mathrm{~cm}$ in diameter. Reports of successful endoscopic GT removal are remarkably scarce; however, they are vastly outnumbered by case reports documenting unsuccessful attempts at endoscopic removal with or without fragmentation [21]. In a review of 40 cases in whom endoscopic removal had been attempted, only $5 \%$ were successful because trichobezoar fragmentation was considered impossible due to the trichobezoar's size, density and hardness [18]. Regarding the patient in this report, we believe that even if there had been no gastric perforation, endoscopic removal of the GT would not have been possible due to the presence of the large gastrolith. Additionally, fragments of the gastrolith might have migrated through the pylorus after fragmentation, which would have resulted in intestinal obstruction similar to that observed in Bouveret syndrome.

Surgery is indicated when a very large or solid GB causes perforation or hemorrhage, or in the case of Rapunzel syndrome, when there is significant extension of the trichobezoar [11]. Since the advent of minimally invasive surgery, the use of laparoscopic techniques for small to moderate-sized GBs has been proposed [11]. Although studies describe GT removal with use of the laparoscopic approach, the technique requires a significantly longer operation time compared with conventional laparotomy, mostly due to the complexity of the operation [22]. Nevertheless, laparoscopy yields superior cosmetic results, fewer postoperative complications and reduced hospital stays; careful examination of the entire digestive system to prevent secondary intestinal obstruction due to the migration of fragments to the distal bowel is more difficult to realize by laparoscopy than open access $[18,22]$. To remove the largest trichobezoars of the abdominal cavity it is sometimes necessary to extend the initial port wounds, which compromises the cosmetic results [16]. In the patient described here, laparoscopy was discouraged due to the presence of a large GT associated with gastric calculus, the small possibility that the stone could be removed through a single trocar incision, the poor clinical conditions and the presence of generalized peritonitis.

Laparotomy is the most effective and therefore the most common technique in the medical literature $[14,18]$. The conventional approach can be used to remove the GT in $100 \%$ of patients and can be performed rapidly in patients presenting in poor condition [18]. A previous study confirmed the successful removal of large GTs by conventional laparotomy combined with anterior gastrotomy [14]. Due to the high success rate, the 
relatively low complication rate, the simple nature of the operation and the ability to carefully examine the entire gastrointestinal tract for satellites over a short period of time, laparotomy is still widely considered as the treatment of choice for complicated trichobezoar [18].

Although studies of the pharmacotherapy of trichotillomania remain inconsistent, some patients seem to respond to fluoxetine or other serotonin reuptake inhibitors [23]. To decrease recurrence, psychiatric follow-up is indicated, although no conclusion has been reached with respect to the best therapeutic approach [24]. The patient's long-term prognosis is excellent and the need for adequate follow-up should be emphasized to avoid recurrences, although these are rare because the trauma of surgery may prevent another episode [23].

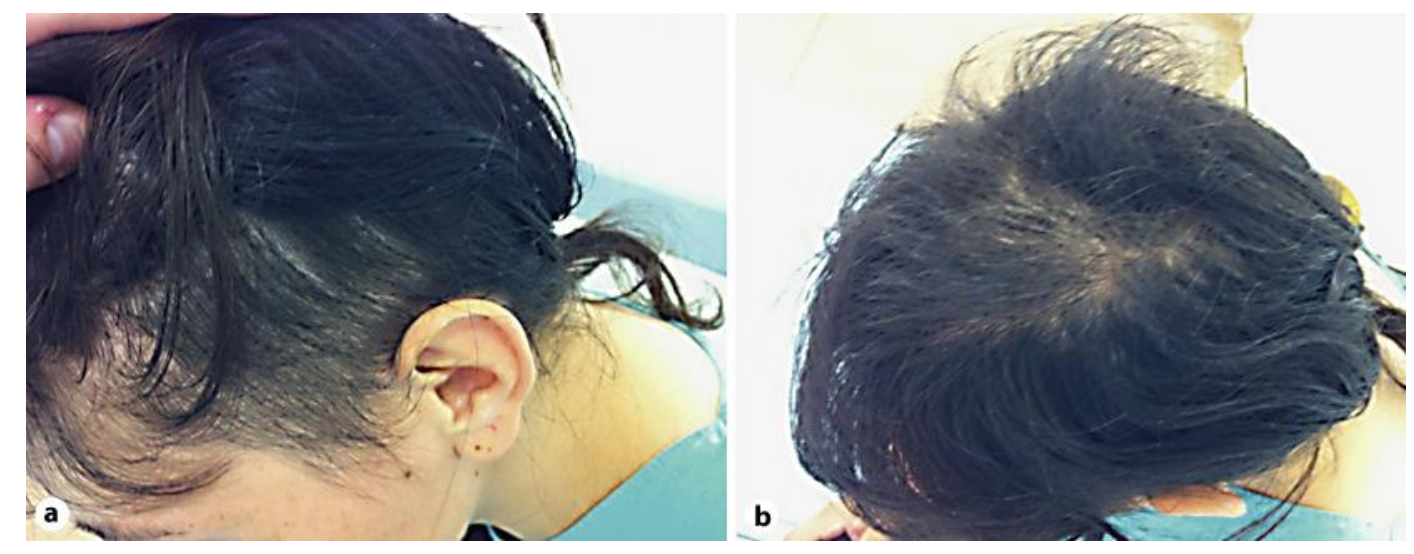

Fig. 1. Photographs of the scalp showing areas of alopecia due to trichotillomania in the temporal and parieto-occipital regions.

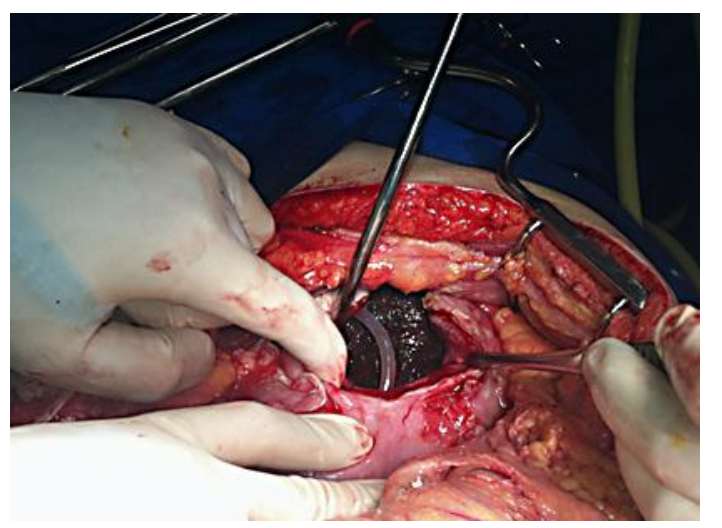

Fig. 2. The photograph shows the anterior gastrotomy and extraction of the tricholithobezoar. 


\begin{tabular}{|c|c|c|c|}
\hline $\begin{array}{l}\text { Case Reports in } \\
\text { Gastroenterology }\end{array}$ & $\begin{array}{l}\text { Case Rep Gastroenterol 2012;6:26-32 } \\
\text { DOI: } 10.1159 / 000336203\end{array}$ & $\begin{array}{l}\text { Published online: } \\
\text { January 13, } 2012\end{array}$ & $\begin{array}{l}\text { (c) } 2012 \text { S. Karger AG, Basel } \\
\text { ISSN } 1662-0631 \\
\text { www.karger.com/crg }\end{array}$ \\
\hline
\end{tabular}
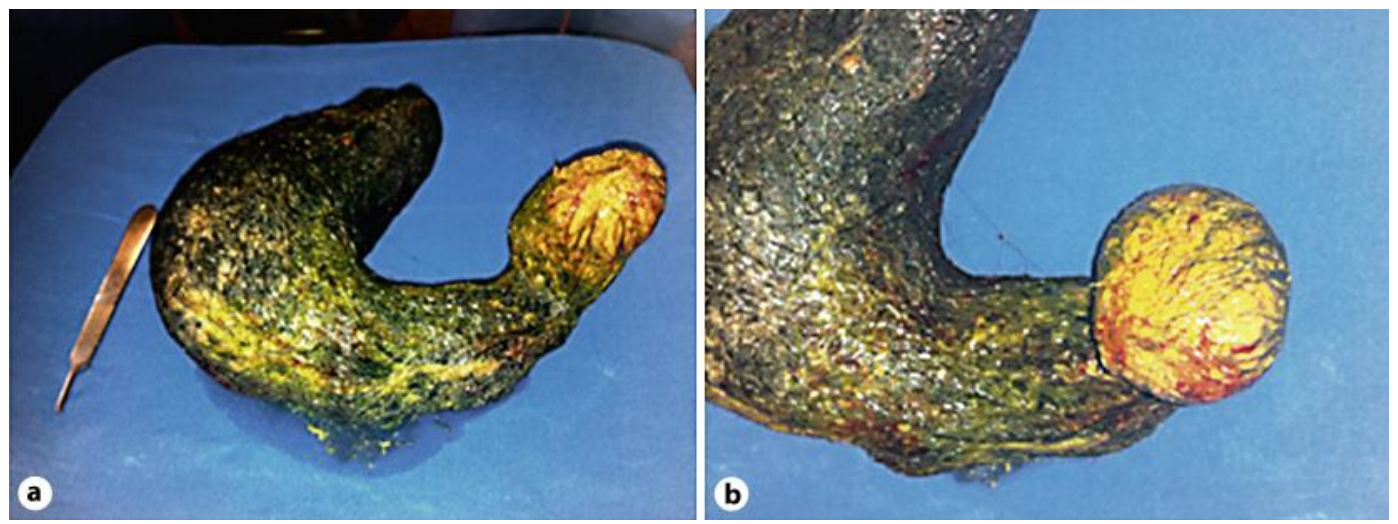

Fig. 3. a Voluminous gastric-shaped trichobezoar measuring $25 \mathrm{~cm}$ in the largest diameter, with a visible yellowish gastrolith on its antral extremity. b Magnified view of the gastric calculus.

\section{References}

1 Ahn YH, Maturu P, Steinheber FU, Goldman JM: Association of diabetes mellitus with gastric bezoar formation. Arch Int Med 1987;147:527-528.

$\checkmark 2$ Hewitt AN, Levine MS, Rubesin SE, Laufer I: Gastric bezoars: reassessment of clinical and radiographic findings in 19 patients. Br J Radiol 2009;82:901-907.

-3 Sumskiene J, Janciauskas D, Pilkauskaite G, Kristalnyj V, Kupcinskas L: An unusual case of bleeding from stomach due to a giant diospyrobezoar. Medicina (Kaunas) 2009;45:476-479.

-4 Coufal NG, Kansagra AP, Doucet J, Lee J, Coimbra R, Bansal V: Gastric trichobezoar causing intermittent small bowel obstruction: report of a case and review of the literature. Case Report Med 2011;2011:217570.

-5 Sehgal VN, Srivastava G: Trichotillomania +/- trichobezoar: revisited. J Eur Acad Dermatol Venereol 2006;20:911-915.

6 Debakey M, Oschner A: Bezoars and concretions, comprehensive review of literature with analysis of 303 collected cases and presentation of 8 additional cases. Surgery 1939;5:132-160.

7 Cohen LJ, Stein DJ, Simeon D, et al: Clinical profile, comorbidity and treatment history in 123 hairpullers: a survey study. J Clin Psychiatry 1995;56:319-326.

8 Bharathan R, Datta S, Webb P, Griffin S: Trichobezoar and postpartum gastric perforation: a case report and brief review of literature. J Obstet Gynaecol 2008;28:438-440.

-9 Nonose R, Valenciano JS, de Souza Lima JS, Nascimento EF, Silva CM, Martinez CA: Jejunal diverticular perforation due to enterolith. Case Rep Gastroenterol 2011;5:445-451.

10 Giese A, Zieren J, Winnekendonk G, Henning BF: Development of a duodenal gallstone ileus with gastric outlet obstruction (Bouveret syndrome) four months after successful treatment of symptomatic gallstone disease with cholecystitis and cholangitis: a case report. J Med Case Reports 2010;4:376.

11 Gonuguntla V, Joshi DD: Rapunzel syndrome: a comprehensive review of an unusual case of trichobezoar. Clin Med Res 2009;7:99-102.

12 Naik S, Gupta V, Naik S, Rangole A, Chaudhary AK, Jain P, Sharma AK: Rapunzel syndrome reviewed and redefined. Dig Surg 2007;24:157-161.

13 Agrawal V, Joshi MK, Jain BK, Gupta A: Plasticobezoar - another new entity for Rapunzel syndrome. Ind J Pediatr 2009;76:229-230.

14 Erzurumlu K, Malazgirt Z, Bektas A, Dervisoglu A, Polat C, Senyurek G, Yetin I, Ozkan K: Gastrointestinal bezoars: A retrospective analysis of 34 cases. World J Gastroenterol 2005;11:1813-1817.

15 Alsafwah S, Alzein M: Small bowel obstruction due to trichobezoar: Role of upper endoscopy in diagnosis. Gastrointest Endosc 2000;52:784-786.

16 Vaughan ED Jr, Sawyers JL, Scott HW Jr: The Rapunzel syndrome. An unusual complication of intestinal bezoar. Surgery 1968;63:339-343. 
17 Martinez CAR, Waisberg J, Palma RT, Silva FZ, Cimerman G, Goffi FS: Morphometric study of gastric mucosa in dogs submitted to proximal gastric vagotomy, splenectomy or proximal gastric vagotomy associated with splenectomy. Acta Cir Bras 2002;17:289-298.

18 Gorter RR, Kneepkens CMF, Mattens ECJL, Aronson DC, Heij HA: Management of trichobezoar: case report and literature review. Pediatr Surg Int 2010;26:457-463.

19 Tamulevichiute DI, Vitenas AM: Bezoars and calculi of the gastrointestinal tract. Klin Med (Mosk) 1981;59:34-38.

20 Saeed ZA, Ramirez FC, Hepps KS: A method for the endoscopic retrieval of trichobezoars. Gastrointest Endosc 1993;39:698-700.

21 Van Gossum A, Delhaye M, Cremer M: Failure of non-surgical procedures to treat gastric trichobezoar. Endoscopy 1989;21:113.

-22 Yau KK, Siu WT, Law BK, Cheung HY, Ha JP, Li MK: Laparoscopic approach compared with conventional open approach for bezoar induced small bowel obstruction. Arch Surg 2005;140:972-975.

-23 Swedo SE, Leonard HL, Rapoport JL, Lenane MC, Goldberger EL, Cheslow DL: A double-blind comparison of clomipramine and desipramine in the treatment of trichotillomania (hair pulling). N Engl J Med 1989;321:497-501.

-24 Lopes LR, Oliveira PSP, Pracucho EM, Camargo MA, Coelho Neto JS, Andreollo NA: The Rapunzel syndrome: an unusual trichobezoar presentation. Case Report Med 2010;2010:841028. 